\title{
Empreendedorismo cultural e turismo: perspectivas para desenvolvimento das indústrias criativas no bairro da Madre Deus, São Luís (Maranhão, Brasil) \\ Cultural and tourism entrepreneurship: prospects for developing creative industries in the Madre Deus neighborhood of São Luís (Maranhão, Brazil)
}

\author{
Conceição de Maria Belfort de Carvalho!', Kláutenys Dellene Guedes Cutriml, Sarany Rodrigues da Costa ${ }^{1}$ \\ Universidade Federal do Maranhão. São Luís, Maranhão, Brasil
}

\begin{abstract}
Resumo: $\bigcirc$ estudo tem por objetivo identificar como o bairro da Madre Deus, localizado em São Luís, capital maranhense, tem desenvolvido esforços para vencer desafios próprios a um empreendedorismo cultural e à formatação de produtos turísticos de cunho criativo. $\bigcirc$ bairro é um dos mais antigos e o maior polo de manifestações populares, ele mantém harmonia com as festas e constitui-se, o ponto central de um complexo turístico-cultural relevante. As análises qualitativodescritivas que compõem os dados da pesquisa foram realizadas a partir de entrevistas concedidas por representantes de setores criativos selecionados. A análise foi feita a partir da articulação entre as informações obtidas na pesquisa bibliográfica e nos dados colhidos. Os empreendedores entrevistados indicaram alguns desafios para a consolidação do setor criativo, tais como a inexistência de parcerias efetivas com os órgãos de fomento à cultura e ao turismo, a falta de integração entre produtores, mestres e artistas populares, empreendedores culturais e a cadeia produtiva do turismo local, bem como a escassez de recursos financeiros. Tais desafios podem se constituir em estímulos para a disseminação de um ambiente favorável à inovação e à criatividade no bairro, desde que se amplie a capacidade empreendedora local.
\end{abstract}

Palavras-chave: Turismo cultural. Empreendedorismo. Bairros tradicionais.

Abstract: This study investigates how the Madre Deus neighborhood of São Luís, capital of the state of Maranhão, has developed efforts to overcome its own challenges to cultural entrepreneurship and shape creative tourism products. This neighborhood is one of the oldest in the city and the largest center for popular demonstrations; it maintains harmony with celebrations and is the focal point of an important complex for tourism and culture. The qualitative and descriptive analyses that comprise the study data are based on interviews with representatives from selected creative sectors. The analysis was based on the connection between the results of the bibliographic research and the data collected. The interviewed entrepreneurs indicated some challenges in establishing the creative sector, such as the lack of effective partnerships with agencies promoting culture and tourism, the lack of integration between producers, established "masters" and popular artists, cultural entrepreneurs and the productive chain of local tourism, as well as the scarcity of financial resources. These challenges can be a stimulus to disseminate an environment conducive to innovation and creativity in this neighborhood, if local entrepreneurial capacity is expanded.

Keywords: Cultural tourism. Entrepreneurship. Traditional neighborhoods.

CARVALHO, Conceição de Maria Belfort de; CUTRIM, Kláutenys Dellene Guedes; COSTA, Sarany Rodrigues da. Empreendedorismo cultural e turismo: perspectivas para desenvolvimento das indústrias criativas no bairro da Madre Deus, São Luís (Maranhão, Brasil). Boletim do Museu Paraense Emílio Goeldi. Ciências Humanas, v. 12, n. 2, p. 629-646, maio-ago. 2017. DOI: http://dx.doi.org/10.1590/ 1981.81222017000200020.

Autora para correspondência: Conceição de Maria Belfort de Carvalho. Universidade Federal do Maranhão. Travessa da Elca, 537, Monte Castelo. São Luís, MA, Brasil. CEP 65030-530 (cbelfort@globo.com).

Recebido em 31/03/2016

Aprovado em 28/03/2017

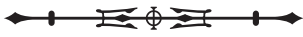




\section{CONSIDERAÇÕES INICIAIS}

A dinâmica das viagens turísticas, na contemporaneidade, motivada por fatores como o interesse pelos modos de vida das comunidades, tem influenciado e estimulado viagens de cunho cultural. Mas as viagens, apesar de movimentarem os destinos, podem afetar de forma negativa os trabalhos de preservação. Paradoxalmente, o turismo também se apresenta como uma possibilidade de preservação, por ser uma atividade capaz de se integrar ao cotidiano do núcleo receptor, ao valorizar a memória e as identidades locais, e por auxiliar na manutenção do legado cultural de forma sustentável.

De forma particular, destaca-se a articulação entre turismo, cultura e desenvolvimento pela força que geram na economia, nas relações sociais e na manutenção e na valorização dos aspectos identitários de um lugar, tais como a gastronomia, o artesanato, as manifestações populares e o patrimônio histórico. Nesse sentido, diversas regiões vêm promovendo o patrimônio cultural enquanto atrativo turístico, possibilitando que as comunidades locais, ao se reconhecerem como elemento integrante do lugar, se envolvam com a sua história e suas tradições, na perspectiva de dinamização econômica e na geração de oportunidades sociais, uma vez que a transformação dos lugares em produtos turísticos pressupõe o surgimento ou a adequação de uma infraestrutura de equipamentos, bens e serviços necessários para a permanência dos visitantes.

segmento do turismo cultural possui ênfase no cotidiano e nas singularidades dos locais visitados, estimulando a preservação do legado cultural, não só em seu aspecto material como também no imaterial. As interações sociais, a vivência e a busca por experiências e troca de elementos culturais são alguns dos aspectos que caracterizam o turismo cultural. Para além do significado econômico, esta atividade é entendida na perspectiva antropológica (Banducci Jr.; Barreto, 2001) como um fenômeno relacional que possibilita encontros entre pessoas de diferentes culturas. Na visão de Pérez (2009, p. 120):
[...] o turismo cultural é entendido como um tipo de turismo "experiencial" através do qual os turistas contactam com produções culturais (ex.: artes visuais, artes manuais, festivais, festividades) e com património cultural (sítios históricos, paisagens, arquitecturas, "bens patrimoniais imateriais").

É a partir das interações entre visitantes e visitados, nos espaços destes últimos - considerados destinos receptores ou núcleos receptores - que o turismo se materializa. Os elementos que particularizam e definem um grupo social são os insumos a partir dos quais se estabelece o denominado produto turístico: as características ambientais, os estilos de vida, as crenças religiosas, o cotidiano de uma comunidade, ou seja, os elementos que formam o patrimônio cultural.

Esse cenário vem acontecendo no estado do Maranhão, em especial na capital São Luís, onde os elementos do patrimônio cultural vêm sendo estruturados como produtos do turismo cultural. Muitas iniciativas estão sendo desenvolvidas pelos órgãos públicos e por empresários do setor, com vistas a melhorar o desempenho da atividade turística local, aumentando o nível de competitividade do destino no mercado, por meio de ações de estruturação da oferta, promoção e comercialização de roteiros e pacotes turísticos, nos quais se destacam várias manifestações importantes da cultura local.

A cidade de São Luís possui atrativos culturais formatados como elementos de oferta turística; além deles, manifestações populares também são instrumentos que favorecem o turismo na cidade e podem se converter em produtos competitivos num mercado em constante transformação. Os elementos culturais são acionados no planejamento estratégico como diferenciadores da oferta, ao lado dos atrativos naturais. Há, no entanto, a necessidade de potencializar a capacidade de promover a emergência de novos roteiros, produtos e serviços na cidade, como estratégia de diferenciação e para promover o aumento da competitividade do produto no mercado.

município detém ainda um diversificado calendário de eventos e de manifestações, o qual está em vias de 
estruturação por parte dos órgãos de fomento ao turismo e à cultura do lugar, com destaque para manifestações de caráter popular. Essas manifestações adensam o centro histórico de São Luís e seus arredores, em especial os bairros da cidade nos quais a diversidade de manifestações reforça o sentido de pertencimento à cultura local.

Diante do contexto de pluralidade dos patrimônios culturais que caracterizam a oferta turística do destino Maranhão, e considerando o cenário de competição entre os lugares turísticos na busca pela captação, retenção e fidelização dos turistas-consumidores, busca-se a conformação de produtos, roteiros, serviços e atrações que garantam a qualidade da viagem turística, o desenvolvimento local integrado e a sustentabilidade dos ecossistemas naturais e dos recursos culturais das regiões. Essa busca tem-se aliado a estratégias que se articulam em torno da criatividade, associada às indústrias criativas.

Mediante a essas considerações, a pesquisa voltou-se para o bairro da Madre Deus, localizado na cidade de São Luís, capital do estado do Maranhão. Local de difusão de manifestações culturais tradicionais, o bairro destaca-se no cenário turístico enquanto elemento de atração de visitantes interessados em conhecer aspectos da cultura local. Nele, constata-se a existência de iniciativas comunitárias em torno de projetos de fortalecimento da memória e da identidade, por meio da atividade turística e do empreendedorismo cultural. Apesar das iniciativas, os projetos ainda estão em fase de implementação.

Sendo assim, a problemática que direcionou esta pesquisa consistiu em observar quais os desafios e as oportunidades enfrentados pelos empreendedores culturais do bairro da Madre Deus para o estabelecimento de produtos turísticos baseados na economia criativa. Dessa forma, o presente artigo objetiva identificar as oportunidades e as dificuldades que se apresentam para o empreendedorismo cultural e para a formatação de produtos turísticos criativos no bairro da Madre Deus, na cidade de São Luís.

Para tanto, buscou-se mapear os atributos culturais, sociais e financeiros presentes neste espaço urbano, além de identificar a visão dos empreendedores culturais do bairro, com o intuito de compreender a dinâmica dos setores criativos e de estabelecer estratégias para o fortalecimento da cultura como recurso para desenvolvimento da cidade (Yúdice, 2004).

$\mathrm{Na}$ perspectiva teórica da pesquisa, utilizou-se como referências sobre indústrias criativas as discussões de Reis e Urani (2011); em se tratando do uso dos termos empreendedorismo e empreendedorismo cultural, buscou-se as análises de Rae (2005) e Bilton (2008). Permeia ainda esta pesquisa a relação entre criatividade, inovação e turismo, sendo este compreendido a partir da abordagem antropológica presente nos estudos de Banducci Jr. e Barretto (2001) e Pérez (2009).

Na pesquisa de campo, realizou-se o mapeamento das atividades criativas do bairro da Madre Deus e procedeu-se à realização de entrevistas junto aos moradores ligados aos setores criativos. Entende-se que a formatação de produtos criativos associados à atividade turística pode se traduzir em ferramenta para a diversificação das atividades produtivas do bairro e para o fortalecimento da identidade cultural local.

\section{INDÚSTRIAS CRIATIVAS, EMPREENDEDORISMO E TURISMO CULTURAL: ENFOQUES E RELAÇÕES}

O surgimento do termo indústrias criativas ocorreu em 1994, na Austrália, ganhando ampla visibilidade no Reino Unido a partir de 1997. Ao longo da primeira década do século XXI, o termo foi sendo alvo de inúmeros debates e, posteriormente, foi ganhando novos contornos, evoluindo para a concepção de cidades ou de espaços criativos (Reis; Urani, 2011). As indústrias criativas envolvem setores artísticos, econômicos, mídias digitais, e têm como núcleo a criatividade humana. Elas concentram-se em quatro grandes áreas - serviços, conteúdos, experiências e originais -, de acordo com o BOP Consulting (2010), conforme apresentado na Figura 1, na qual são demonstradas as interseções que existem entre elas. 


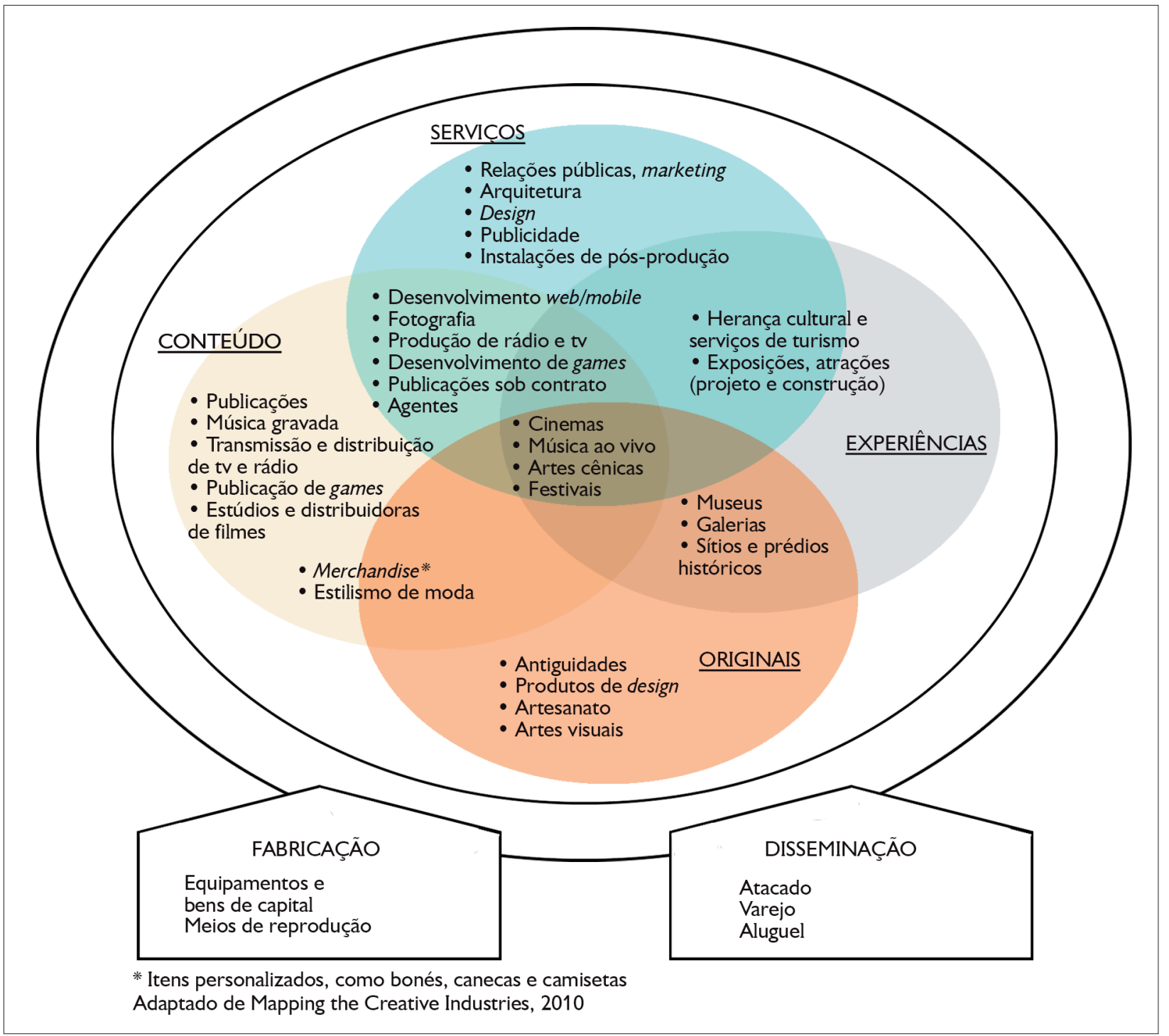

Figura 1. Distribuição das atividades que compõem as indústrias criativas. Fonte: BOP Consulting (2010).

Reis e Urani (2011) argumentam que as indústrias criativas referem-se aos setores e, sobretudo, aos processos que utilizam como insumos a informação, a criatividade e a cultura, com vistas a produzir bens e serviços com valor econômico e simbólico, sendo esta uma produção que valoriza a singularidade. Tal entendimento é reforçado por Howkins (2001), considerado o pai do conceito de economia criativa, e que a define como algo conduzido por indivíduos que utilizam a imaginação e seu capital intelectual nos processos de criação, produção e distribuição de produtos e serviços.

Edna dos Santos-Duisenberg (Fariello, 2011) concebe a economia criativa a partir de um ponto de vista holístico e multidisciplinar, que mantém diálogo com a economia como um todo, a cultura e a tecnologia. De acordo com Deheinzelin (2011, p. 1), a economia criativa abrange uma "[... ] cadeia de geração de valor que, através de etapas em que ocorrem sinergias com outras áreas, ativa e concretiza

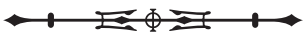


as reservas de valor/patrimônios intangíveis como cultura, conhecimento, criatividade, experiência, valores.".

É importante destacar, nesse contexto, o papel desempenhado pela globalização, que modificou as relações socioespaciais por meio da incorporação de novas tecnologias, ampliou os processos de intercâmbio cultural, além de ter redefinido a importância dos setores ligados à cultura na dinamização econômica das regiões.

Nesse sentido, as indústrias criativas configuram-se, na atualidade, como estratégias para o desenvolvimento das sociedades na era do conhecimento, na medida em que a associação entre arte, economia, cultura, lazer, entretenimento e tecnologia enseja novos enfoques de abordagens e amplia as oportunidades de geração de trabalho, riqueza, emprego, por meio de experiências baseadas no empreendedorismo cultural, criativo e inovador.

A criatividade pode conduzir ao aparecimento de comunidades criativas em distintos territórios, regiões, cidades ou bairros, denominados por Selada e Cunha (2010, p. 3) de "ecossistemas criativos", que, segundo eles, possuem três características essenciais: talentos ou classe criativa; economia - indústrias criativas; e lugares-territórios criativos, os quais se influenciam mutuamente.

A cidade de Medelin, na Colômbia, é um forte exemplo de um ecossistema criativo. De cidade mais violenta do mundo transformou-se em cidade da inovação, graças à transformação por que passou em sua estrutura socioeconômica, resultado de parcerias com setores da indústria criativa, com a comunidade local e a prefeitura. Tais elementos foram fundamentais para a recuperação da cidade, que registrou aumento do Produto Interno Bruto (PIB) e queda da desigualdade econômica e social.

Tais debates inspiram-nos a pensar sobre a realidade local, sobre seu potencial de criatividade, bem como a respeito das oportunidades que as indústrias criativas e a economia da criatividade geram na maximização dos níveis de competitividade de um destino no mercado. No âmbito do turismo, a economia criativa requer, de todos os setores que a envolvem, um engajamento para fazê-la funcionar de forma efetiva.

No âmbito das trocas materiais e simbólicas que caracterizam as sociedades contemporâneas, sobressai-se a atividade turística, fomentadora do contato intercultural, na medida em que o turismo transforma as particularidades de um dado local em produto para o consumo. Ruschmann (1997, p. 26) destaca que o produto turístico é "amálgama de elementos tangíveis e intangíveis, centralizados numa atividade específica e numa determinada destinação, facilidades e a formas de acesso, as quais o turista compra a combinação de atividades e arranjos". Na visão de Pérez (2009, p. 111), "o consumidor compra, não bens e serviços, mas a vivência de experiências e sensações".

Lage e Milone (2000) entendem atrativos turísticos como sendo o conjunto de elementos e recursos presentes em determinados destinos, capazes de motivar o deslocamento de indivíduos para essas áreas, promovendo a atividade turística. Desse modo, a constitui-se como matéria-prima do turismo, os elementos diferenciadores que servem de base para a preparação dos produtos turísticos. São, segundo Beni (1998, p. 153), "as fontes de atração que sustentam os deslocamentos de pessoas com finalidades especificamente turísticas". A cultura, portanto, é vista como recurso e insumo para o desenvolvimento da atividade turística:

\begin{abstract}
O turismo cultural promove o contato entre culturas diferentes, a compreensão do patrimônio, além de surgir como alternativa para a geração de emprego e renda, e dinamização das economias locais. Essa atividade tende a potencializar os elementos que formam o patrimônio de uma comunidade, seja por meio da revitalização de conjuntos arquitetônicos, refuncionalização de prédios com importância histórica e cultural, seja pelo fortalecimento das celebrações populares tradicionais. (Carvalho; Silva, 2014, p. 573).
\end{abstract}

Nesse sentido, o turismo possibilita novos usos e funções aos elementos que formam a paisagem urbana e o patrimônio cultural local, além de uma nova imagem, que atrai recursos e capital externos para o fomento às 
atividades de lazer e de consumo, típicos das indústrias criativas: eventos e exposições, museus, além de projetos e ações de revitalização de conjuntos arquitetônicos. Na visão de Moesch (2002, p. 20):

[...] o turismo é um campo de práticas históricosociais, que pressupõem o deslocamento do(s) sujeito(s), em tempos e espaços produzidos de forma objetiva, possibilitador de afastamentos simbólicos do cotidiano, coberto de subjetividades, portanto, explicitadores de uma nova estética diante da busca do prazer.

Complementando esse entendimento, Perez (2009) sistematiza uma série de abordagens acerca do fenômeno turístico, entendendo-o como momento de suspensão do cotidiano mediante a busca pelo consumo das representações simbólicas das localidades - imagens, objetos e símbolos -, com repercussões de ordem social, econômica, política e cultural, sendo seus efeitos ora positivos, ora negativos.

Por meio do segmento do turismo cultural, as cidades tonam-se produtos culturais lúdicos, símbolos de lazer, entretenimento, diversão, estimulando experiências estéticas diferenciadoras, atraindo, assim, um público consumidor interessado em conhecer as particularidades culturais de uma comunidade. Por intermédio da criação de experiências inusitadas - por exemplos, a visitação turística em favelas do Rio de Janeiro ou a visitação em comunidades quilombolas e indígenas -, o turista tende a apresentar um comportamento ativo, atuando em coautoria com as comunidades locais na produção e no consumo turístico.

A inovação agregada à criatividade consiste em propor produtos e serviços com forte apelo emocional junto ao público consumidor, bem como a adoção de práticas sustentáveis no uso de matérias-primas. Soma-se a isso a noção de que a rede de negócios estabelecida possui como objetivo não apenas a rentabilidade para os potenciais investidores, mas a sustentabilidade e o desenvolvimento das localidades envolvidas. Inovação e criatividade estão intrinsecamente relacionadas aos conceitos de empreendedorismo e de empreendedorismo cultural.

Este termo tem sido amplamente discutido e, embora existam inúmeras definições, uma das pioneiras e que reflete bem a realidade do povoado que se configura como objeto desta pesquisa é a definição de Schumpeter (1997, p. 60), para quem "[...] o empreendedor é aquele que destrói a ordem econômica existente pela introdução de novos produtos e serviços, pela criação de novas formas de organização ou pela exploração de novos recursos e materiais.".

Analisando essa definição, percebemos que empreender não significa necessariamente introduzir algo novo no mercado, mas promover transformações nos produtos já existentes e nos processos gerenciais, detectando novas oportunidades mercadológicas.

Já Carton et al. (1998, p. 360) definem o empreendedorismo e o empreendedor como:

[...] a procura de uma oportunidade descontinuada envolvendo a criação de uma organização com a expectativa de criação de valor para os participantes. O empreendedor é o indivíduo que identifica a oportunidade, reúne os recursos necessários, cria e é responsável pela performance da organização.

Assim, na contemporaneidade, assume-se que o empreendedorismo constitui-se num fenômeno econômico, cultural, psicológico e sociológico, vinculado ao surgimento de novas perspectivas de negócios. Ao lado deste termo, outros, como inovação e criatividade, estão intrinsecamente relacionados e garantem às empresas que se mantenham ativas no mercado, posicionando-se junto aos seus clientes reais ou potenciais.

De acordo com Schumpeter (1997), a inovação faz-se presente em empresas que possuem práticas de gestão, ideias e técnicas diferenciadas, as quais resultam em novos produtos ou novos processos. Para o autor, as inovações podem acontecer pela introdução de novos produtos e serviços, de um novo método de produção, abertura de um novo mercado, descoberta de uma nova matéria-prima ou, ainda, reorganização de uma indústria. 
Para Sauaia e Sylos (2000), os empreendedores precisam saber lidar com as oportunidades e com os desafios apresentados por um mercado competitivo e caracterizado por sucessivas transformações. Os desafios incluem:

[...] a) a exigência crescente dos clientes; b) a personalização de produtos e serviços voltados para nichos de mercado; c) a evolução da ciência e da tecnologia em ritmo acelerado; [além de] d) o estabelecimento de parcerias entre empresas; e) o crescimento da consciência ecológica; e f) a exigência cada vez maior da prática da ética empresarial. (Sauaia; Sylos, 2000, p. 3).

Estabelecendo-se uma convergência com o setor de turismo, evidenciamos uma relação mútua entre turismo, criatividade e inovação. Por ser um setor extremamente volátil, as localidades que desejam ampliar seu potencial de competitividade devem buscar a permanente qualificação profissional dos agentes que atuam nos setores direta e indiretamente relacionados com o turismo. A personalização ou a customização dos produtos e serviços apresentase também como uma proposta que torna os artigos diferenciados. Destacam-se, ainda, estratégias de fidelização dos clientes/turistas e a rentabilidade dos negócios.

Tais iniciativas podem ocorrer por meio de arranjos colaborativos, alianças e parcerias estratégicas na formatação de negócios que acrescentem experiências diferenciadoras, inusitadas e memoráveis aos visitantes, ao mesmo tempo em que se diversifica a oferta de atrativos e de possibilidades de consumo desses elementos, sejam eles naturais e/ou culturais.

De acordo com Cassarotto Filho e Pires (2001, p. 107):

Em casos de grandes potencialidades naturais ou na quase total restrição das mesmas, a potencialidade básica de qualquer local, região ou país está assentada em sua população, ou mais amplamente, em seu ambiente: a interação dessa gente, por meio de sua cultura, com o território e suas relações externas. Essa é a alavanca principal do processo de desenvolvimento e que requer grandes esforços de fomento e promoção.

Considerando que o empreendedor pode ser definido como alguém que cria algo novo ou que promove melhorias em produtos e serviços já consolidados no mercado, o empreendedor cultural seria aquele que, por meio de sua criatividade, identifica novas oportunidades mercadológicas nos setores de cultura, lazer e entretenimento, mobiliza os recursos criativos em prol da criação e do gerenciamento de empreendimentos e negócios culturais de forma sustentável, possuindo, ainda, a função primordial de ser o articulador da cadeia de geração de valor nas indústrias criativas.

O termo empreendedorismo cultural foi utilizado inicialmente nos trabalhos sobre a dinâmica das organizações culturais, de autoria de Dimaggio e Powell (1991), na década de 1980. Na década seguinte, teóricos como Rae (2005) e Bilton (2008) passaram a aplicar o conceito de empreendedorismo cultural em estudos sobre indústrias criativas.

Considerando que os produtos e serviços oriundos das indústrias criativas, além do caráter econômico, são detentores de um forte conteúdo simbólico e estético, o empreendedor cultural possui uma relação diferenciada com o mercado, atuando em todo o processo criativo, detendo-se nas distribuição e venda dos produtos e serviços criativos:

\begin{abstract}
Nas indústrias criativas, a criatividade é a essência do negócio e são os indivíduos criativos que dão origem à concepção e desenvolvimento dos produtos. Entretanto, a produção depende de outros atores, como promotores, gestores, produtores, trabalhadores técnicos e distribuidores. Além disso, a valorização do produto depende do trabalho de outras pessoas, como críticos e outros profissionais dos meios de comunicação. (Souza, 2011, p. 31).
\end{abstract}

Segundo Bilton (2008), a atuação dos empreendedores culturais não se concentra em grandes empresas. A geração de valor na cadeia produtiva acontece de forma dispersa na rede de relações estabelecidas entre os empreendedores culturais e outros profissionais de pequenas e médias empresas, especializadas nas fases de criação e de distribuiç̧ão dos bens e serviços criativos. No que tange às relações com os consumidores, os produtos criativos não findam no ato de consumo; o consumidor torna-se coparticipante da cadeia 
de valor. Souza (2011, p. 69) elenca algumas características do trabalho no âmbito das indústrias criativas:

Perspectivas financeiras - instabilidade, baixas remunerações, carreira incerta, diferenças substanciais em termos de reputação e ganhos (as desigualdades de remuneração não são apenas toleradas, mas asseguradas ou mesmo celebradas);

Motivação - forte motivação intrínseca, a criação é um elemento essencial na vida do artista, recompensas não-econômicas (a satisfação pessoal, intelectual e estética é mais importante do que outras necessidades, como satisfazer um cliente ou pagar as contas);

Necessidade de reconhecimento - importância da exposição do trabalho e da criação de obras reconhecidas como de um criador particular (o reconhecimento do nome no campo é um dos únicos meios de fazer valer o status profissional e é a demonstração de que a arte é legítima e valorizada pela sociedade em geral);

Condições de trabalho - individualismo, autonomia, responsabilidade, risco, flexibilidade, adaptabilidade, habilidades de pensamento divergente e intuitivo, valorização do talento individual como fator essencial da produção.

Diante do exposto, o interesse despertado pelas indústrias criativas na promoção do desenvolvimento socioeconômico - cultural suscita uma reflexão acerca de sua importância no âmbito do segmento do turismo cultural. Para diversos autores, sobretudo da vertente antropológica, o turismo é uma atividade de interação entre anfitriões e hóspedes, e, enquanto tal, uma série de inter-relações de fundo econômico, ambiental, político, social e cultural decorre dessa prática.

turismo cultural pode ser entendido como um segmento que possibilita aos visitantes o contato com aspectos da cultura local - material e intangível - e a ampliação de seus conhecimentos, na perspectiva de maior intercâmbio e compreensão intercultural. Ressalta-se que o turismo cultural possui uma nuance educacional verificada pela possibilidade de o turista ampliar seus conhecimentos sobre a cultura visitada por meio da interação com a comunidade e do contato com os elementos do patrimônio cultural - festas e danças populares tradicionais, gastronomia, musicalidade, religiosidade, museus e centros de cultura etc. Nesse sentido, interessa aos turistas culturais a manutenção dos patrimônios como objetos de apreciação e fruição cultural. De acordo com Costa (2009, p. 190):

\begin{abstract}
O turismo cultural pode ser compreendido como um segmento da atividade turística que, por meio da apreciação, da vivência e da experimentação direta dos bens do patrimônio cultural, material e imaterial, e da mediação da comunicação interpretativa, proporciona aos visitantes a participação em um processo ativo de construção de conhecimentos sobre o patrimônio cultural e sobre seu contexto sócio-histórico. Em última escala, este processo auxiliará na produção de novos conhecimentos e a conservação dos bens visitados.
\end{abstract}

Dentre as oportunidades propiciadas pela relação turismo e cultura, podemos citar a valorização dos patrimônios culturais locais mediante à revitalização de áreas históricas, que passam a se constituir em espaços de lazer e de entretenimento, à dinamização econômica, à elevação da autoestima e ao fortalecimento da identidade comunitária. No entanto, o aproveitamento dos patrimônios culturais enquanto recursos ou elementos de atratividade turística necessita ser planejado de forma sustentável, a fim de que a dinâmica cultural de uma comunidade não sofra interferências decisivas em virtude da presença de visitantes.

Com base nos aspectos apresentados, consideramos que o bairro da Madre Deus configura-se como lócus potencial para o desenvolvimento do turismo cultural, o qual, vinculado aos princípios da economia criativa e da capacidade empreendedora dos agentes locais, poderá se tornar um espaço de referência para o turismo na cidade de São Luís, Maranhão.

\section{DESENHO METODOLÓGICO DA PESQUISA}

A pesquisa possuiu um caráter exploratório, com vistas ao aprofundamento da temática levantada - empreendedorismo cultural, turismo e indústrias criativas (Gil, 2002) - e uma abordagem qualitativa, tendo em vista que buscamos

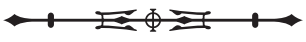


compreender a dinâmica do setor cultural do bairro da Madre Deus a partir da perspectiva dos empreendedores locais, considerando suas crenças e visões de mundo.

Os procedimentos metodológicos obedeceram às seguintes etapas: inicialmente, procedeu-se ao levantamento bibliográfico, visando à apropriação teórica das categorias cultura, economia criativa, indústrias criativas e cidades criativas, turismo cultural, empreendedorismo cultural, disponíveis na literatura nacional e internacional.

Em seguida, procedeu-se à fase de pesquisa de campo, através do mapeamento das atividades criativas existentes no bairro da Madre Deus e da realização de entrevistas com os empreendedores culturais. Para o mapeamento dos espaços e de atividades criativas, utilizou-se como instrumental uma Matriz de Mapeamento de Espaços Criativos, elaborada em oficina durante o I Encontro de Economia Criativa, realizado pelo curso de Bacharelado em Turismo, da Universidade Federal do Maranhão, em 2012, na cidade de São Luís, Maranhão.

A referida matriz é formada por quatro dimensões - cultural, social, financeira e ambiental -, nas quais foram distribuídos os atributos identificados no referido bairro por meio de categoriasexcluir, tais como: talentos/capacidades; patrimônio cultural material/imaterial; existência de ações coletivas organizadas e parcerias; iniciativa empreendedora; estímulo à captação de negócios e investimentos, entre outras.

$\bigcirc$ instrumental possibilitou a sistematização dos dados dos mantenedores do setor cultural e criativo da Madre Deus, bem como das manifestações existentes naquele espaço cultural. Após o mapeamento e a análise dos atributos da matriz, foram aplicados questionários e entrevistas junto aos moradores do bairro, com o objetivo de compreender a dinâmica cultural local.

No levantamento exploratório, identificamos 17 manifestações que constituíram o universo da pesquisa. Considerando que as pesquisas qualitativas dedicam-se a apreender osfenômenos a partir da consulta aos sujeitos que dela participam, optou-se por uma amostra probabilística por julgamento, baseando-se em dois critérios.
O primeiro foi a localização da manifestação: somente foram incluídas na pesquisa os representantes das manifestações localizadas no bairro da Madre Deus; as que estiveram no entorno da área, a exemplo dos bairros Lira e Belira - as quais também são lócus de manifestações culturais -, foram excluídas.

O segundo critério foi a inscrição em órgão de cultura. Foram incluídas as manifestações que estavam inscritas em órgãos tanto do município como do estado. Dessa forma, do universo de 17 manifestações identificadas, apenas 12 localizadas especificamente no bairro da Madre Deus enquadraram-se nos critérios de amostragem e participaram efetivamente da pesquisa. Ressalta-se que as fases de mapeamento de espaços criativos, e de coleta e análise dos dados e informações pertinentes aos representantes dos setores criativos ocorreram entre os meses de dezembro de 2014 a fevereiro de 2015.

As entrevistas semiestruturadas foram realizadas com cada empreendedor cultural no intuito de identificar e de analisar as oportunidades e os entraves no processo de produção de bens criativos, bem como na prestação de serviços turísticos criativos e inovadores. No processo de transcrição das entrevistas, buscou-se analisar a fala dos informantes a partir do seu contexto socioeconômico e cultural, extraindo as "expressões-chave" do discurso, permitindo o resgate essencial do conteúdo discursivo e mais clareza na argumentação, conforme apontado por Lefévre et al. (2000).

Para tanto, foram articulados discursos dos empreendedores do bairro com os referenciais teóricos utilizados no decorrer da pesquisa bibliográfica, a fim de estabelecer uma visão geral dos setores criativos associados à atividade de turismo cultural local. A partir do desenho metodológico proposto por Lefévre et al. (2000), expomos os passos utilizados para análise e discussão dos dados:

a) Leitura do conjunto de resposta de cada questão;

b) Leitura de cada resposta em particular, sublinhando as expressões-chave; 
c) Análise das expressões-chave, buscando agrupar as semelhantes em conjunto(s) homogêneo(s);

d) Identificação e nomeação da ideia central ou ancoragem do conjunto, com o objetivo de reunir num só quadro as expressões-chave da mesma ideia central ou da mesma ancoragem;

e) Construção dos discursos do sujeito coletivo de cada quadro obtido na etapa d.

Dessa forma, no tópico a seguir são apresentados os principais resultados e discussões da pesquisa a partir do mapeamento das atividades e/ou dos serviços criativos, das manifestações culturais existentes e das atividades desenvolvidas pelos empreendedores entrevistados, a fim de potencializar as indústrias criativas no bairro da Madre Deus e de superar eventuais entraves à sua consolidação.

\section{RESULTADOS E DISCUSSÃO}

\section{MADRE DEUS: ESPAÇO DE DIVERSIDADE E CRIATIVIDADE}

Localizada à sudoeste da cidade de São Luís, a Madre Deus é formada por pequenos bairros como Lira, Belira, Codozinho, Goiabal, Macaúba, São Pantaleão, Fonte do Bispo, Vila Passos, Vila Bessa, e sua formação está relacionada ao crescimento da cidade ao longo do século XVIII. Durante o final do século XIX e início do XX, a Madre Deus revestiu-se de importância econômica, em virtude do estabelecimento de fábricas, como a Companhia de Fiação e Tecelagem São Luís, também conhecida como Fábrica São Luís, e a Companhia de Fiação e Tecidos de Cânhamo, atual CEPRAMA, localizadas na rua de São Pantaleão. Atualmente, o bairro da Madre Deus constitui-se num dos principais lócus de convergência de diversas manifestações e atividades culturais da cidade, sobretudo no período do carnaval e das festividades juninas. Trata-se de um complexo turístico-cultural cujas bases foram construídas a partir da mobilização e da organização comunitária, sendo considerado centro de atração de visitantes ao longo dos principais períodos festivos da cidade.
Dentre as manifestações carnavalescas, têm destaque fofões, tribos de índios, casinha da roça, tambor de crioula, bandas e blocos tradicionais, como a Máquina de Descascar Alho, o Bicho Terra e os Fuzileiros da Fuzarca, blocos afro-maranhenses, escolas de samba, como a Turma do Quinto e a Flor do Samba. No mês de junho, o bairro é local de encontro de brincantes de bumba-meu-boi, na capela de São Pedro.

Além do patrimônio imaterial, o bairro abrange bens de importância histórica e cultural, tais como a Casa das Minas e a Casa de Nagô, espaços de religiosidade da cultura afro-maranhense; a sede do Boi Barrica, um dos principais grupos parafolclóricos do estado; e o Centro de Comercialização de Produtos Artesanais do Maranhão (CEPRAMA), antiga fábrica têxtil da Companhia de Fiação e Tecidos de Cânhamo e que atualmente serve como local de exposição e de comercialização do artesanato maranhense.

As atividades culturais da Madre Deus são construídas por meio do intercâmbio de informações, elementos materiais e simbólicos, e estão envoltas por uma rede de sociabilidade e de integração de diferentes grupos ou atores sociais, por meio dos quais verifica-se um cenário diversificado de personagens que interagem em prol de fé, devoção, louvação aos santos ou padroeiros, lazer, diversão ou de simplesmente festejar entre amigos. São esses personagens que, materializando as práticas culturais, tornam-se os responsáveis pela manutenção dessas tradições, reforço da identidade cultural e inovações.

Tais manifestações possuem elementos de agregação popular e trazem o sentido de comunidade, considerando que, nas atividades, sagradas ou profanas, as culturas populares são acionadas como reveladores da identidade de cada grupo ou indivíduo participante dessas manifestações. $\bigcirc$ sentimento de comunhão é compartilhado pelos moradores e produtores culturais do bairro, e os laços identitários são reforçados e passados de geração em geração, como condição de sobrevivência da cultura popular.

Pontua-se ainda o significado econômico dessas manifestações populares tradicionais, posto que existe 
uma rede de relações comerciais, envolvendo o processo de confecção de indumentárias, adornos e adereços dos brincantes das festas carnavalescas e juninas. Durante tais acontecimentos, há um processo de mobilização dos agentes em prol do fortalecimento da economia, seja por intermédio da inserção das manifestações culturais nos meios de comunicação de massa, do estabelecimento de uma economia informal, que gera emprego e renda para muitos moradores durante a realização desses eventos populares, seja pela utilização dessas manifestações como atrativos turísticos para os visitantes.

A gestão da produção cultural local envolve inciativas comunitárias, por meio da ação conjunta de artistas populares, empresários, intelectuais, gestores públicos municipais e estaduais, dentre outros. $\bigcirc$ desenvolvimento de atividades culturais, tais como roteiros turísticos, circuitos carnavalescos e oficinas, reflete o potencial para a consolidação de um 'ecossistema criativo' no bairro.

Diante desse cenário, a pesquisa de campo buscou identificar as oportunidades para o desenvolvimento do setor de economia criativa, bem como os principais desafios enfrentados pelos empreendedores culturais com vistas à formação de produtos turísticos criativos. A Matriz de Mapeamento de Espaços Criativos (Carvalho; Mendonça, 2014) sistematiza os principais recursos e atributos criativos existentes no bairro, conforme demonstra o Quadro 1.

Conforme se observa na primeira dimensão da matriz - a cultural -, o bairro da Madre Deus possui características de uma classe criativa em formação: poetas, compositores, músicos, cantores, contadores de história e escritores são fomentadores da dinâmica dos espaços culturais locais, a partir da confluência de saberes e fazeres tradicionais ligados ao carnaval e ao período junino.

Esses atores sociais são catalisadores de recursos criativos e estimulam setores de lazer e de entretenimento direta e indiretamente relacionados às indústrias criativas, com destaque para a realização de eventos religiosos e culturais, gastronomia e artesanato. Soma-se a isso a existência de lugares de memória - casas de culto afro e as fábricas -, que fortalecem a identidade do bairro e contribuem para o sentimento de pertencimento ao patrimônio cultural local.

Os setores ligados às manifestações culturais do período carnavalesco e junino são os mais desenvolvidos e podem agregar valor a partir da adoção dos princípios e das características da economia criativa; outras áreas como gastronomia, música popular e artesanato podem ser foco de estímulo, criando uma rede de solidariedade, além de dinamizar ciclos voltados para a produção de serviços de conteúdo estético e simbólico, valorizados tanto por parte dos turistas como da comunidade local e adjacências.

No quadro geral das manifestações mapeadas, considera-se que estas apresentam três diferenciais imanentes aos setores criativos: o primeiro refere-se à sua natureza simbólica e interpretativa, bem como às suas repercussões nos processos de produção, consumo e inovação; o segundo diz respeito aos valores e estilos de vida típicos dos empreendedores culturais; e o terceiro diz respeito à imprevisibilidade da demanda.

$\mathrm{Na}$ dimensão social, observamos processos de articulação comunitária e desenvolvimento de espaços de discussão e de planejamento das ações culturais, por meio do Conselho Cultural da Madre Deus e da Associação de Moradores. Existem relações de parcerias junto à Secretaria Municipal de Turismo, Serviço Brasileiro de Apoio às Micro e Pequenas Empresas (SEBRAE), Secretaria Estadual de Turismo e Secretaria Estadual de Cultural.

$\mathrm{Na}$ dimensão financeira, constata-se que os grupos apresentam objetivos e metas empreendedoras, destacando-se a Cia. Barrica e os Feras; no entanto, estes, de um modo geral, dispõem de reduzidas linhas de financiamento para a realização de projetos e empreendimentos culturais. No que se refere à existência de ambiente favorável ao desenvolvimento de pesquisas e à geração de negócios, a maioria dos representantes culturais entrevistados não possui uma clara percepção acerca da importância do saber fazer tradicional do bairro como 
Quadro 1. Matriz de Mapeamento de Espaços Criativos. Fonte: Carvalho e Mendonça (2014).

\begin{tabular}{|c|c|c|c|}
\hline Cultural & Social & Financeiro & Ambiental \\
\hline 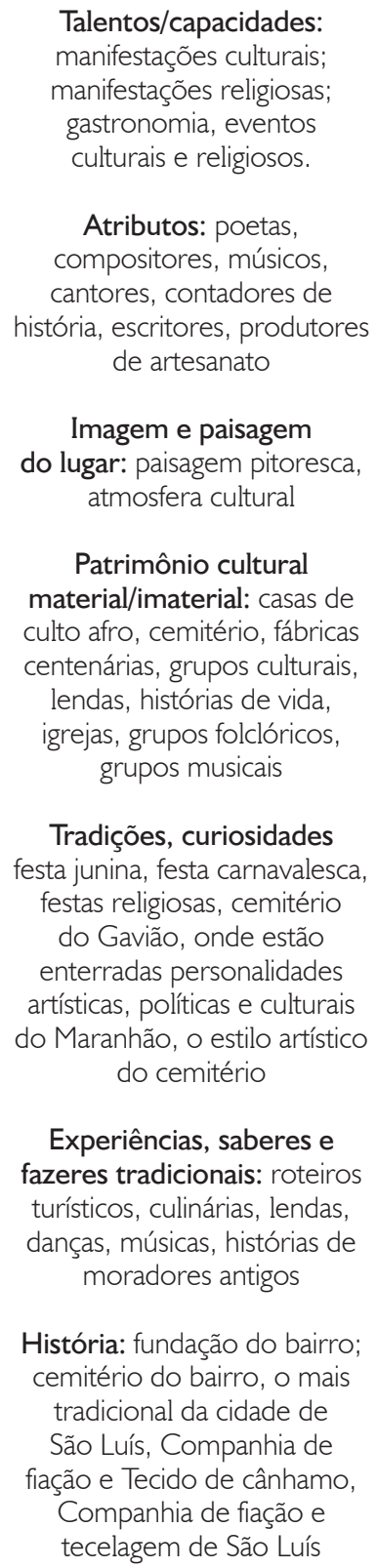 & $\begin{array}{l}\text { Ação coletiva organizada: } \\
\text { Iniciativa de Instância de } \\
\text { Governança, Conselho } \\
\text { Cultural da Madre Deus, } \\
\text { Associação dos Moradores } \\
\text { Instituições parceiras: } \\
\text { Secretaria Municipal de } \\
\text { Turismo, SEBRAE, Secretaria } \\
\text { Estadual de Turismo, } \\
\text { Secretaria Estadual de } \\
\text { Cultural, Secretaria } \\
\text { Municipal de Cultural } \\
\text { Lideranças existentes: } \\
\text { Conselho Cultural da } \\
\text { Madre Deus } \\
\text { Instrumentos de } \\
\text { comunicação: carro } \\
\text { de som, reuniões } \\
\text { Ferramentas de acesso } \\
\text { e visibilidade: o centro de } \\
\text { produção artesanal do bairro } \\
\text { faz parte do roteiro turístico } \\
\text { de São Luís } \\
\text { dos eventos locais, músicos } \\
\text { Existência de comunidades } \\
\text { étnicas: existência de } \\
\text { casas de culto afro } \\
\text { Grupos/rede: nível de } \\
\text { articulação da classe criativa } \\
\text { como artesãos, organizadores }\end{array}$ & $\begin{array}{l}\text { Recursos existentes/ } \\
\text { ações de contrapartida: } \\
\text { Secretaria de Cultura do } \\
\text { Estado e do Município } \\
\text { Linhas de financiamentos: } \\
\text { apenas dois grupos buscam } \\
\text { financiamentos em banco e } \\
\text { de acordo com algum evento } \\
\text { específico que queiram } \\
\text { promover } \\
\text { Iniciativa empreendedora } \\
\text { e vontade: algumas } \\
\text { manifestações têm iniciativas } \\
\text { empreendedoras como } \\
\text { Os Feras, Cia. Barrica, } \\
\text { Quadrilha Sertaneja Rosa } \\
\text { Amarela, entretanto, em } \\
\text { relação ao universo de } \\
\text { grupos, podemos considerar } \\
\text { o estímulo à captação de } \\
\text { negócios e de investimentos } \\
\text { fraco } \\
\text { financiamento. Motivação para } \\
\text { fazer os cursos } \\
\text { para elaboração de projetos e } \\
\text { Ambiente favorável ao } \\
\text { desenvolvimento de } \\
\text { negácímulo à captação de } \\
\text { pesquisas e à geração de } \\
\text { negócios culturais: } \\
\text { o ambiente é favorável ao } \\
\text { desenvolvimento de pesquisa } \\
\text { e à geração de negócios } \\
\text { culturais, entretanto a maioria } \\
\text { das manifestações não tem a } \\
\text { percepção de que é possível } \\
\text { fazer da cultura um meio de } \\
\text { renda } \\
\text { framenta instumentalizã̃o }\end{array}$ & $\begin{array}{c}\text { Espaços ociosos disponíveis: } \\
\text { praças, fábricas abandonadas, } \\
\text { ruas, Largo do Caroçudo } \\
\text { Matérias-primas: } \\
\text { patrimônio material e } \\
\text { patrimônio imaterial } \\
\text { Locais especiais: } \\
\text { Praça da Saudade, Largo } \\
\text { do Caroçudo, igrejas, Vista, } \\
\text { Centro de Artesanato do } \\
\text { Maranhão, Praça Demerval } \\
\text { Equipamentos culturais e } \\
\text { de lazer: Praça da Saudade, } \\
\text { Largo do Caroçudo, Centro } \\
\text { de Artesanato do Maranhão, } \\
\text { Casa Barrica, Largo de São } \\
\text { Pedro, algumas ruas do bairro }\end{array}$ \\
\hline
\end{tabular}

insumo para a geração de renda e para a consequente melhoria da qualidade de vida local.

$\bigcirc$ bairro possui espaços de sociabilidade e de reciprocidade cultural, notadamente a Praça da Saudade, o
Largo do Caroçudo, o Largo de São Pedro e o CEPRAMA, os quais definem a dinâmica da paisagem urbana e das relações estabelecidas entre os empreendedores e os equipamentos culturais e de lazer existentes.

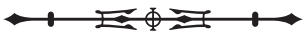


A configuração urbana, os elementos do patrimônio material e os bens imateriais tornam-se suportes para o surgimento de ações empreendedoras e criativas locais, a exemplo de performances de artistas locais, oficinas de artesanato e produção de documentários, por exemplo. Na esteira de Costa (2012, p. 95):

[...] torna-se evidente a necessidade de se criar instrumentos educativos e pedagógicos que, usando o patrimônio cultural como ferramenta de aprendizagem, demonstrem que o processo de salvaguardar e de preservar a memória coletiva é uma atitude de muitos atores sociais trabalhando em conjunto. É necessário que especialistas em patrimônio e membros da coletividade estejam envolvidos em um trabalho de educação permanente, no qual os sujeitos se reconheçam como parte do patrimônio global.

Estabelece-se, portanto, uma noção mais abrangente do patrimônio cultural do bairro e de sua apropriação turística na forma de bens culturais criativos, sendo necessário criar mecanismos que favoreçam o reconhecimento dos setores criativos como parte integrante da memória e da identidade dos grupos culturais.

\section{A PERSPECTIVA CRIATIVA DOS EMPREENDEDORES DA MADRE DEUS}

Diante das reais possibilidades de estabelecimento de uma economia criativa por meio do turismo cultural no bairro da Madre Deus, busca-se a visão daqueles que atuam direta e indiretamente no campo cultural do bairro, levando-se em consideração os fatores que estimulam as inciativas empreendedoras, as relações comunitárias estabelecidas na dinâmica de produção de bens e serviços, bem como as suas expectativas para o desenvolvimento do turismo cultural e das indústrias de criatividade no bairro.

Os entrevistados foram unânimes em afirmar que o patrimônio cultural, a criatividade e a diversidade constituem-se como recursos diferenciadores e determinantes para o surgimento e a consolidação das indústrias criativas no bairro da Madre Deus, entretanto a maioria dos empreendedores culturais observou que não existe uma rede de colaboração e de troca de experiências entre os atores sociais atuantes nos diferentes setores da economia do bairro capaz de estimular os talentos locais e as ações empreendedoras.

Nos entremeios dos discursos, notamos que os empreendedores da Madre Deus não possuem uma clara distinção entre arte e negócio, embora reconheçam que os trabalhos realizados no cotidiano das manifestações tendem a impulsionar a economia da comunidade. No geral, sentem-se integrados ao bairro em virtude das atividades artísticas que exercem, ressaltando que as manifestações culturais são entendidas como extensão da sua identidade enquanto sujeitos, e os objetivos que envolvem tais iniciativas nem sempre equivalem à busca por retorno financeiro, mas sim por satisfação pessoal.

Uma das características dos empreendedores culturais revela-se na capacidade que possuem para detectar oportunidades, mobilizar agentes e recursos, bem como assumir riscos do empreendimento. $O$ empreendedor cultural é entendido como agente mobilizador de recursos criativos, econômico-financeiros, sendo, articulador de redes com o objetivo de identificar oportunidades de negócios no campo cultural, de lazer e entretenimento, além de formular estratégias de desenvolvimento do negócio (Limeira, 2008).

A visão dos entrevistados enquadra-se nas características vinculadas ao trabalho dos empreendedores culturais definidas por Wilson e Stokes (2002): (1) demarcação confusa entre consumo e produção; (2) demarcação confusa entre o que é ou não trabalho; (3) combinação entre valores individualistas e trabalho colaborativo; e (4) ser parte de uma comunidade criativa maior.

A atração e a retenção de talentos é uma das características predominantes das cidades e dos espaços criativos. Especificamente na Madre Deus, foram identificados atores sociais que apresentam potencial para ser articuladores de redes de economia criativa no bairro, servindo de importantes referenciais no campo da cultura. Na visão de Leal (2007, p. 7), os gestores culturais possuem a função de 
[...] estabelecer um diálogo entre os patrocinadores, meios de comunicação (formas de divulgação), público consumidor e artistas e equipamentos, de forma que estabeleça um modo de tornar sustentáveis os profissionais, projetos e instituiç̧ões do campo cultural.

O processo de agregação de valor aos produtos e serviços oferecidos torna-se possível mediante o estímulo permanente para a criatividade e a geração de novas ideias, valorizando o capital intelectual dos artistas e mantenedores da cultura na Madre Deus. Guardando-se as especificidades das manifestações culturais existentes na área, percebe-se a existência de características comuns: a busca constante pela inovação e o estímulo às ideias criativas entre brincantes e produtores culturais.

Cauduro (2003, p. 3) apresenta outras características que definem as atividades artísticas e culturais e que se enquadram à realidade do bairro, a saber:

Gerenciamento descontínuo [...]; Gerenciamento de trabalhadores ocasionais ou temporários [...]; Ambiente de constante inovação $[\ldots] ;[\ldots]$ cada oferta de produto é única [...]; Mercado complexo e fragmentado $[\mathrm{e}][\ldots]$ forte concorrência $[. .$.

De acordo com as entrevistas realizadas, a articulação em torno dos setores criativos no bairro ainda é incipiente, necessitando de maior participação de agentes da comunidade e de outros locais, visando estimular os setores, atrair investimentos externos, além de buscar por políticas culturais adequadas que favoreçam o espírito empreendedor e deem suporte para a identificação de novas oportunidades de negócios culturais.

Os modelos de negócios criativos primam pela articulação intersetorial e pela participação dos ativos humanos na condução de estratégias de inserção de produtos e serviços criativos nos processos de produção, circulação e consumo. As inovações tecnológicas, a busca pela criatividade, a adaptação dos produtos e serviços às necessidades de mercado redirecionam a procura por um aumento da competitividade dos negócios, sendo a inovação e a criatividade as características fundamentais para a sobrevivência no mercado.

Em se tratando dos pequenos empreendedores, a inovação vinculada à criatividade consiste em propor produtos e serviços com forte apelo emocional junto ao público consumidor, na adoção de práticas sustentáveis no uso de matérias-primas e na noção de que a rede de negócios estabelecida possui como objetivo não apenas a rentabilidade para os empreendedores/ investidores, mas a sustentabilidade e desenvolvimento das localidades envolvidas.

Os principais obstáculos identificados entre os produtores culturais para a formação de uma cultura empreendedora na Madre Deus referem-se à inexistência de parcerias efetivas com os órgãos de fomento à cultura e ao turismo, à falta de integração entre produtores, mestres e artistas populares, empreendedores culturais e cadeia produtiva do turismo local, bem como à escassez de recursos financeiros.

De acordo com Marinho (2009, p. 257), algumas alternativas podem ser tomadas com vistas a aprimorar o setor criativo, potencializando os seus benefícios na revitalização de áreas turísticas:

[...] (1) articular diferentes formas de manifestações culturais que se complementam, gerando economias de escala; (2) ampliar as oportunidades de ofertas culturais em determinadas regiões, atraindo consumidores que buscam turismo e entretenimento responsável; (3) promover a convergência de ações para a criação de novos mercados; e (4) validar que os insumos básicos desse mercado são a inovação e a imaterialidade para a geração de novos produtos e negócios.

Cabe ressaltar que nos processos de inovação, a cooperação entre as diferentes organizações e o compartilhamento de conhecimentos agregam valor à produção, ampliando a competitividade. O estabelecimento de redes de negócios que tendem a valorizar a reciprocidade, as conexões e as redes de relacionamento garante a redução de custos, a agilidade no atendimento das demandas 
dos consumidores e a ampliação das oportunidades mercadológicas. Para Yúdice (2004, p. 405), comunidades e artistas "[...] exploram comunidades baseados na culturacomo-recurso para solucionar problemas sociais [...]".

$\mathrm{Na}$ visão dos empreendedores entrevistados, as manifestações tradicionais do bairro garantem a sustentabilidade financeira apenas nos períodos de carnaval e de São João, devendo ser mobilizadas estratégias conjuntas e integradas que possibilitem maior visibilidade aos negócios culturais, bem como o aprimoramento das habilidades dos empreendedores no que se refere aos processos de planejamento e de gestão dos empreendimentos culturais.

O ciclo da criatividade urbana proposto por Landry (2006) pode ser adaptável à realidade do bairro da Madre Deus, na medida em que algumas das etapas que integram esse modelo apresentem ressonância entre os empreendedores entrevistados: 1) reforçar a capacidade de gerar ideias; 2) transformar ideias em realidade; 3) neworking e circulação de ideias; 4) providenciar plataformas de entrega; e 5) criar públicos e mercados.

Sendo assim, a comunidade da Madre Deus deve buscar mecanismos de apoio, tanto em nível estadual quanto em nível federal. Segundo Dolabela (2003, p. 77), o empreendedor promove inovações e mudanças na forma gerencial, " [...] seja na forma de administrar, vender, fabricar, distribuir, seja na forma de fazer propaganda dos seus produtos e/ou serviços, agregando novos valores".

Nesse contexto, ações de acompanhamento dos setores criativos, promoção de eventos, captação de recursos para o desenvolvimento de projetos culturais são fundamentais para garantir a sustentabilidade financeira dos empreendedores, evitando-se também a sua dependência excessiva em relação ao setor público; a oferta de cursos e oficinas de capacitação nas áreas de gestão e de empreendedorismo tende estimular a abertura de novos negócios, com vistas a dinamizar a economia da cultura local.

Ainda, a consolidação de produtos criativos pressupõe maior aproximação entre os empreendedores culturais e o público consumidor, por meio de atividades laboratoriais e experiências práticas nas quais possa ocorrer o intercâmbio de conhecimentos entre produtores criativos, turistas e comunidade local. Nesse contexto, os entrevistados foram favoráveis em desenvolver estratégias de revitalização do bairro e de fortalecimento dos saberes e fazeres tradicionais, por intermédio da oferta de cursos, workshops e oficinas.

Os empreendedores entrevistados foram unânimes ao afirmar a importância do turismo no processo de consolidação das inciativas desta natureza na comunidade, pois já se observa que o bairro da Madre Deus está inserido nos roteiros turísticos da cidade e muitas iniciativas nas áreas de cultura e entretenimento desenvolvidas pelos empreendedores culturais estão vinculadas aos benefícios proporcionados pela presença de visitantes, notadamente os de interesse cultural.

fortalecimento das indústrias criativas contribui para o desenvolvimento e para a revitalização de áreas e de espaços urbanos que as abrigam, aumentando a sua competitividade também no mercado turístico: "[...] as actividades criativas reforçam a qualidade de vida das cidades, facilitando a revitalização do espaço urbano e a modelação da identidade da cidade em termos de competição pelos talentos e investimentos [...]" (Selada; Cunha, 2010, p. 3).

Nesse sentido, as entrevistas sugeriram algumas inciativas para se pensar a economia criativa em associação com o turismo cultural, dentre as quais destacamos: ações de revitalização do bairro; estruturação de equipamentos e espaços criativos, a fim de desenvolver vínculos afetivos entre os jovens da comunidade; implantação de incubadoras, projetos de apoio às capacidades criativas; desenvolvimento de novas tecnologias; e capacitação nas áreas de empreendedorismo e captação de recursos:

Transformar em qualidade de vida a enorme riqueza potencial, representada pela nossa diversidade, nossos recursos culturais e naturais, só será possível com ações e políticas adequadas, focadas em desenvolvimento e sustentabilidade. Ações que para serem efetivas devem contemplar não apenas o aspecto econômico, mas as outras

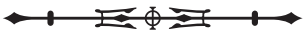


dimensões em que a Economia Criativa atua: o simbólico, o social e o ambiental. Ações cuja eficácia está vinculada à inovação, à visão de futuro, desenvolvendo modelos adequados ao século $X X I$, e à construção do mundo que desejamos. (Deheinzelin, 2008, p. 27).

Assim, com base nas entrevistas realizadas, observase a necessidade de ampliar a competência relacional dos empreendedores do bairro da Madre Deus, por meio de melhorias nos processos de comunicação, do fortalecimento de parcerias e alianças estratégicas internas e de instituições de fomento às indústrias criativas, em nível local e nacional, para fins de concretização da economia criativa no bairro.

\section{CONSIDERAÇÕES FINAIS}

O desenvolvimento socioeconômico de uma comunidade perpassa pela mobilização e organização dos atores sociais em torno de atitudes e ações empreendedoras baseadas no potencial criativo do patrimônio material e imaterial, vislumbrando-se potencialidades e transformando-as em estratégias de inserção no mercado. Os setores da denominada economia criativa revelam-se como estratégia de criação de produtos e serviços com valores simbólicos capazes de gerar emprego e renda para as comunidades elevando consequentemente a qualidade de vida.

No intuito de compreender a dinâmica do bairro da Madre Deus, na cidade de São Luís, e o perfil inicial dos empreendedores culturais locais, constatou-se que a maioria é autônomo em relação ao mercado, vinculandose a atividades que compõem a denominada economia criativa, tais como eventos culturais, artesanato, lazer e entretenimento, além de saberes, fazeres e manifestações populares, que, articulados, podem se constituir como fatores de propulsão para o turismo cultural na cidade.

Foram identificadas iniciativas pontuais visando ao desenvolvimento dos setores criativos, além de desafios para a consolidação da classe criativa, notadamente no que se refere à maior articulação entre os talentos locais com a adoção de uma postura empreendedora e proativa, no sentido de promover criatividade individual, empresarial e urbana na consolidação de produtos turísticos competitivos e sustentáveis.

Além disso, o monitoramento contínuo dessas manifestações enquanto produto turístico constitui-se em estratégias de valorização e manutenção dessas tradições culturais. $\bigcirc$ acompanhamento das modificações da cultura, provocadas ou não pela presença dos visitantes e de suas interações com os grupos culturais, contribui para o entendimento da dinâmica de cada manifestação, além de garantir a sua continuidade, assim como sua sustentabilidade econômica e social.

Diante do potencial para o setor criativo da Madre Deus, faz-se necessário um planejamento voltado para a oferta cultural, o qual deve ser constituído por um conjunto de iniciativas e estratégias para a formatação dos produtos criativos, fortalecimento da identidade local e aumento da qualidade da experiência turística do visitante. $O$ planejamento da oferta cultural do bairro pressupõe a participação dos atores com que se materializam as práticas culturais locais, por meio da constituição de espaço de diálogo e da gestão compartilhada dos atrativos culturais.

Paralelamente, para que a indústria da criatividade se sobressaia no mercado, o planejamento deve ser uma ferramenta de identificação das oportunidades, ao traçar o perfil dos empreendedores culturais e diagnosticar as principais tendências do setor, estruturando os atrativos, equipamentos e serviços turísticos, de forma a contemplar os anseios e as necessidades do público consumidor.

Torna-se necessário atrair investimentos para o bairro da Madre Deus, capacitar e manter os empreendedores culturais, estimulando a formatação, circulação e consumo de bens, serviços e experiências criativas em estreita relação com a atividade turística.

A economia criativa, como modelo paradigmático, direciona-se para a valorização da criatividade e da cultura local, para o desenvolvimento das competências empreendedoras, bem como para a integração entre os

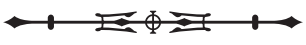


setores público, privado e não governamental. Em sua interface com o turismo, ela pressupõe a participação da comunidade na tomada de decisões ao longo de todo o processo de planejamento e de implementação de produtos turísticos experienciais e criativos, avaliação e controle das atividades, de forma a possibilitar o desenvolvimento em bases locais.

\section{AGRADECIMENTOS}

Ao Ministério da Cultura(MinC), por intermédio da Secretaria de Economia Criativa (SEC), e ao Conselho Nacional de Desenvolvimento Científico e Tecnológico (CNPq).

\section{REFERÊNCIAS}

BANDUCCI JR., Álvaro; BARRETTO, Margarita (Org.). Introdução. In: BANDUCCI JR., Álvaro; BARRETTO, Margarita. Turismo e identidade local: uma visão antropológica. Campinas, SP: Papirus, 2001. p. 7-20.

BENI, Mário Carlos. Análise estrutural do turismo. 9. ed. São Paulo: Senac São Paulo, 1998. 523 p.

BILTON, Chris. cultures of management: cultural policy, cultural management and creative organizations. In: FAMANI, V. V.; BALA KRISHNA, A. V.(Ed.). Cultural industries: perspectives and experiences. Hyderabad, India: Icfai University Press, 2008. p. 24-44. Disponível em: <http://wrap.warwick.ac.uk/60691/> . Acesso em: 10 mar. 2016.

BOP CONSULTING. Mapping the creative industries: a toolkit. London: British Council, 2010. (Creative and Cultural Economy Series, 2).

CARTON, Robert B.; HOFER, Charles W.; MEEKS, Michael D. The entrepreneur and entrepreneurship: operational definitions of their role in society. Athens: The University of Georgia, 1998. Disponível em: <https://www.researchgate.net/publication/252370481_THE ENTREPRENEUR_AND_ENTREPRENEURSHIP_OPERATIŌNAL DEFINITIONS_OF_THEIR_ROLE_IN_SOCIETYY $>$. Acesso em: 10 mar. 2016.

CARVALHO, Conceição de Maria Belfort de; MENDONÇA, Sâmia Cristini Pereira. Empreendedorismo cultural: perspectivas para desenvolvimento do Turismo Cultural no bairro da Madre Deus em São Luís-MA. Relatório de Pesquisa. São Luís, 2014. Disponível em: < http://recria.ihac.ufba.br/wp-content/uploads/2015/03/Relatorioanexo-40892320130.pdf>. Acesso em: 28 ago. 2016.

CARVALHO, Karoliny Diniz; SILVA, Ricardo Torres. El teatro urbano como experiencia turística: un análisis del potencial del municipio del Alcântara, Maranhão, Brasil. Estudios y Perspectivas em Turismo, Buenos Aires, v. 23, n. 3, p. 566-584, jul. 2014.
CASSAROTTO FILHO, Nelson; PIRES, Luiz Henrique. Rede de pequenas e médias empresas e desenvolvimento local: estratégias para a conquista da competitividade global com base na experiência italiana. 2. ed. São Paulo: Atlas, 2001.

CAUDURO, Flavia Ferro. Competências organizacionais e gerenciais associadas a gestão de empresas de produção artística e cultural: um estudo exploratório. In: ENCONTRO DA ASSOCIAÇÃO NACIONAL DOS PROGRAMAS DE PÓSGRADUAÇÃO EM ADMINISTRAÇÃO, 27, 2003, Atibaia. Resumos... Rio de Janeiro: ANPAD, 2003. p. 1-16.

COSTA, Flávia Roberta. Turismo e patrimônio cultural: interpretação e qualificação. São Paulo: SENAC, 2009.

COSTA, Heloisa Helena Fernandes Gonçalves da. Museologia e patrimônio nas cidades contemporâneas: uma tese sobre gestão de cidades sob a ótica da preservação da cultura e da memória. Boletim do Museu Paraense Emílio Goeldi. Ciências Humanas, Belém, v. 7, n. 1, p. 87-101, jan.-abr. 2012. DOI: http://dx.doi. org/10.1590/S1981-81222012000100007.

DEHEINZELIN, Lala. O Estado e a economia criativa numa perspectiva de sustentabilidade e de futuro. 2011. Disponível em: <http://aladeheinzelin.com.br/wp-content/uploads/2012/08/80Estado-e-a-Economia-Criativa-numa-perspectiva-de-sustentabilidadee-futuroset11.pdf > . Acesso em: 2 maio 2016.

DEHEINZELIN, Lala. Economia criativa, sustentabilidade e desenvolvimento local. In: REIS, Ana Carla Fonseca; DEHEINZELIN, Lala (Ed.). Cadernos de economia criativa: economia criativa e desenvolvimento local. Vitória: SEBRAE, 2008. p. 27-40.

DIMAGGIO, Paul Joseph; POWELL, Walter W. The iron cage revisited: institucional isomorphism and collective rationality in organization fields. In: DIMAGGIO, Paul Joseph; POWELL, Walter W. (Ed.). The new institucionalism in organizational analysis. Chicago: University of Chicago Press, 1991. p. 63-82.

DOLABELA, Fernando. Empreendedorismo, uma forma de ser: saiba o que são empreendedores individuais e empreendedores coletivos. Brasília: Aed, 2003.

FARIELLO, Danilo. UNCTAD: Temos muito mais a oferecer do que café, suco e minério. Entrevista com Edna dos Santos-Duisenberg. iG, Brasília, 21 jun. 2011. Disponível em: <http://economia. ig.com.br/empresas/unctad-temos-muito-mais-a-oferecer-doque-cafe-suco-e-minerio/n1597039670251.html>. Acesso em: 16 out. 2014.

GIL, Antonio Carlos. Como elaborar projetos de pesquisa. 4. ed. São Paulo: Atlas, 2002.

HOWKINS, John. The creative economy: how people make money from ideas. London: Penguin, 2001.

LAGE, Beatriz Helena Gelas; MILONE, Paulo Cesar. Turismo: teoria e prática. São Paulo: Atlas, 2000.

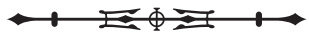


LANDRY, Charles. The art of city making. London: Earthscan, 2006.

LEAL, Nathalia Oliveira. Gestão cultural: um perfil dos gestores de teatros de Salvador. In: ENCONTRO DE ESTUDOS MULTIDISCIPLINARES EM CULTURA, 3., 2007, Salvador. Tópico Temático... Salvador: UFBA, 2007. p. 1-12.

LEFÉVRE, Fernando; LEFÉVRE, Ana Maria Cavalcante; TEIXEIRA, Jorge Juarez Vieira (Org.). O discurso do sujeito coletivo: uma nova abordagem metodológica em pesquisa qualitativa. Caxias do Sul: EDUCS, 2000

LIMEIRA, Tania Maria Vidigal. Empreendedor cultural: perfil e formação profissional. In: ENCONTRO DE ESTUDOS MULTIDISCIPLINARES EM CULTURA, 4., 2008, Salvador. Tópico Temático... Salvador: UFBA, 2008. p. 1-15.

MARINHO, Heliana. Cidades criativas, turismo e revitalização urbana. In: REIS, Ana Carla Fonseca; MARCO, Kátia de (Org.). Economia da cultura: ideias e vivências. Rio de Janeiro: Publit, 2009. p. 251-262.

MOESCH, Marutschka. A produção do saber turístico. São Paulo: Contexto, 2002.

PÉREZ, Xerardo Pereiro. Turismo cultural: uma visão antropológica. El Sauzal: ACA y PASOS, RTPC. 2009. 307 p. (Colección Pasos, n. 2).

RAE, David. Cultural diffusion: a formative process in creative entrepreneurship? International Journal of Entrepreneurship and Innovation, London, v. 6, n. 3, p. 185-192, 2005.
REIS, Ana Carla Fonseca; URANI, André. Cidades criativas: perspectivas brasileiras. In: REIS, Ana Carla Fonseca; KAGEYAMA, Peter (Org.). Cidades criativas: perspectivas. São Paulo: Garimpo de Soluções, 2011. Disponível em: <http://issuu.com/catracalivre/ docs/ivro_cidades_criativas/35>. Acesso em: 12 mar. 2015.

RUSCHMANN, Doris Van de Meene. Turismo e planejamento sustentável: a proteção do meio ambiente. São Paulo: Papirus Editora, 1997. (Coleção Turismo).

SAUAIA, Antônio Carlos Aidar; SYLOS, Andréa de Lima e. Plano empresarial em 4 etapas. Caderno de Pesquisas em Administração, São Paulo, v. 1, n. 11, p. 1-11, jan.-mar. 2000.

SCHUMPETER, A. Joseph. Teoria do desenvolvimento econômico. São Paulo: Editora Nova Cultura Ltda., 1997.

SELADA, C.; CUNHA, I. Criatividade em áreas de baixa densidade: o caso da vila de Óbidos. [S.l.]: INTELI - Inteligência em Inovação/Centro de Inovação, 2010.

SOUZA, Cristina Lyra Couto de. Panis et Ars: artistas e gestores nas indústrias criativas. 2011. 222 f. Tese (Doutorado em Administração de Empresas) - Pontifícia Universidade Católica do Rio de Janeiro, Rio de Janeiro, 2011.

WILSON, Nicholas; STOKES, David. Cultural entrepreneurs and creating exchange. Journal of Research in Marketing and Entrepreneurship, London, v. 4, n. 2, p. 37-52, 2002.

YÚDICE, George. A conveniência da cultura: usos da cultura na era global. Belo Horizonte: UFMG, 2004.

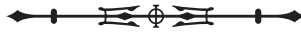

